\title{
Soil Morphologic Properties and Cattle Stocking Rate Affect Dynamic Soil Properties
}

\author{
Heidi J. Schmalz, ${ }^{1}$ Robert V. Taylor, ${ }^{2}$ Tracey N. Johnson, ${ }^{3}$ Patricia L. Kennedy, ${ }^{4}$ Sandra J. DeBano, ${ }^{5}$ \\ Beth A. Newingham, ${ }^{6}$ and Paul A. McDaniel
}

Authors are ${ }^{1}$ Monitoring Coordinator and ${ }^{2}$ Regional Ecologist, The Nature Conservancy, Enterprise, OR 97828, USA; ${ }^{3}$ Postdoctoral Research Associate, Zoology and Physiology, University of Wyoming, Laramie, WY 82071, USA; ${ }^{4}$ Professor, Department of Fisheries and Wildlife, Eastern Oregon Agricultural Research Center, Oregon State University, Union, OR 97883, USA; ${ }^{5}$ Associate Professor, Department of Fisheries and Wildife, Hermiston Agricultural Research and Extension Center, Oregon State University, Hermiston, OR 97838, USA; ${ }^{6}$ Assistant Professor, Department of Forest, Rangeland and Fire Sciences, University of Idaho, Moscow, ID 83844, USA; and ${ }^{7}$ Professor, Department of Plant, Soil, and Entomological Sciences, University of Idaho, Moscow, ID 83844, USA.

\begin{abstract}
Soil properties that influence the capacity for infiltration and moisture retention are important determinants of rangeland productivity. Monitoring effects of grazing on dynamic soil properties can assist managers with stocking rate decisions, particularly if monitoring takes into account environmental variability associated with inherent soil morphological properties. On a Pacific Northwest Bunchgrass Prairie in northeast Oregon, we applied three cattle stocking rates $(0.52,1.04$, and 1.56 animal unit months $\cdot \mathrm{ha}^{-1}$ ) and an ungrazed control in a randomized complete block design for two 42-d grazing seasons and measured the change in four dynamic soil properties: soil penetration resistance, soil aggregate stability, bare ground, and herbaceous litter cover. To address apparent environmental heterogeneity within experimental units, we also utilized a categorical soil factor (termed Edaphic Habitat Types or EHT), determined by characterizing soil depth, texture, and rock fragment content at sample sites. Stocking rate did not affect extent of bare ground or soil aggregate stability. Stocking rate had a significant effect on penetration resistance, which was greatest at the high stocking rate $\left(1.6 \mathrm{~J} \cdot \mathrm{cm}^{-1} \pm 0.1 \mathrm{SE}\right)$ and lowest in the control $\left(1.1 \mathrm{~J} \cdot \mathrm{cm}^{-1} \pm 0.1 \mathrm{SE}\right)$. For litter cover, the effects of stocking rate and EHT interacted. In two rocky EHTs, litter cover was highest in the controls $(60 \% \pm 6 \mathrm{SE} ; 50 \% \pm 3 \mathrm{SE})$ and ranged from $27 \% \pm 3 \mathrm{SE}$ to $33 \% \pm 6 \mathrm{SE}$ in the stocking rate treatments. Measures of penetration resistance, aggregate stability, and bare ground were different across EHTs regardless of stocking rate, but did not interact with stocking rate. Our study demonstrates that response of dynamic soil properties to stocking rates should be considered as a useful and accessible approach for monitoring effects of livestock management decisions on rangeland conditions.
\end{abstract}

Key Words: dynamic cone penetrometer, Pacific Northwest Bunchgrass Prairie, soil aggregate stability, soil heterogeneity, soil surface characteristics

\section{INTRODUCTION}

Stocking rate is one of the primary management decisions made by livestock managers for controlling the extent and quality of environmental disturbance incurred by grazing (e.g., Holechek et al. 1995; Walker 1995; Dunn et al. 2010). In an era of management focused increasingly on sustainability, an appropriate stocking rate is theoretically a function of carrying capacity. Since true carrying capacity is challenging to determine, observable surrogates, such as vegetation and soil condition, are invoked to assess trends in rangeland condition (Breckenridge 1994; National Research Council 1994; Pyke and Herrick 2003; Mitchell 2010; Sheley et al. 2011). Soils have been ubiquitously recognized as a critical resource for

Research was funded in part by the National Research Initiative of the USDA Cooperative State Research, Education and Extension Service, Grant 2006-35101-16572; the University of Idaho Student Grant Program, Grant 10835; and The Nature Conservancy.

At the time of the research, Schmalz was a graduate student in the Environmental Science Program at the University of Idaho, Moscow, ID 83844, USA.

Correspondence: Robert V. Taylor, 906 S River St, Enterprise, OR 97828, USA. Email: rtaylor@tnc.org

Manuscript received 30 March 2012; manuscript accepted 28 March 2013

(c) 2013 The Society for Range Management sustaining productivity and for providing indications of broader ecosystem function and resilience (Smith et al. 1995; Herrick 2000; Pyke et al. 2002), particularly in water-limited environments where soils and soil surface conditions largely determine water infiltration and moisture retention. Soil morphologic properties influence erosion resistance and capacity for water infiltration and retention; these inherent properties cannot be changed by management. However, dynamic soil properties, such as compaction, aggregate stability, soil organic matter content, soil surface cover, and soil water content, can change over short periods of time and are affected by grazing management (Greenwood and McKenzie 2001; Teague et al. 2011; Weber and Gokhale 2011; Zhao et al. 2011). In applied grazing research, assessing dynamic soil properties related to erosion potential and capacity to capture and retain water offers an alternative to direct measurements of soil water content, infiltration, runoff, or erosion. This approach provides an opportunity for studying dynamic soil properties where it would otherwise not be feasible and allows for larger sample sizes across broader spatial extents.

Two commonly measured near-surface soil characteristics that influence erosion resistance and infiltration capacity are soil resistance to penetration and soil aggregate stability (Herrick et al. 2002; Herrick et al. 2005). Soil compaction, 
which is inferred from penetration resistance, is a direct effect of livestock trampling that causes soil bulk density to increase (Warren et al. 1986; Dormaar and Willms 1998; Daniel et al. 2002) and porosity to decrease (Greenwood et al. 1997; Pietola et al. 2005). These changes in soil physical structure can decrease water infiltration (Gifford and Hawkins 1978; Thurow et al. 1988; Pietola et al. 2005) and inhibit plant root growth (Chen and Weil 2010). Use of the dynamic cone penetrometer to evaluate compaction is relatively new in grazing research, but researchers have demonstrated that penetration resistance is inversely related to infiltration and positively related with runoff and sediment yield (Teague et al. 2008, 2011). Soil aggregate stability should not be utilized as a sole predictor of field-scale runoff or erosion, but the degree of soil aggregation affects several soil processes, including the contributions of various organic matter constituents (Jastrow et al. 1998), maintenance of pore space and infiltration capacity (Wischmeier and Mannering 1969; Blackburn and Pierson 1994), and activity of soil organisms (Wander et al. 1994). Evaluations of soil erosion models for semi-arid lands have found that the soil erodibility factor is strongly correlated with aggregate stability and permeability (Vaezi and Sadeghi 2011). Barthès and Roose (2002) confirmed the strong negative association between aggregate stability and soil loss and runoff at field scales ranging from $\mathrm{m}^{2}$ to ha on a variety of soil types, and recommended the use of aggregate stability as a valid indicator for soil conditions related to runoff and erosion.

Soil surface characteristics, including extent of bare ground and litter cover, can also be used to infer potential for runoff and erosion (Herrick et al. 2002, 2005). The relative extent of bare ground and herbaceous litter cover is known to vary with grazing intensity (Naeth et al. 1991; Northup et al. 2005; Fernandez et al. 2008) and is indicative of the landscape's susceptibility to runoff and erosion. Litter layer in grasslands is a primary factor influencing amount of rainfall that infiltrates the soil, subsequent runoff, and the degree to which moisture is evaporated or retained (Tomanek 1969; Thurow et al. 1986; Naeth and Chanasyk 1995; Chartier et al. 2011). Litter cover on the soil surface also provides a physical barrier to raindrop impact and thus limits the potential for erosion from particle detachment. Litter cover has been shown to significantly reduce soil loss (Benkobi et al. 1993) and runoff (Boeken and Orenstein 2001; Hart and Frasier 2003; Smets et al. 2008). Several other studies emphasizing the importance of vegetation patterns and their contributions to bare ground and litter cover as they affect runoff and erosion on rangelands are reviewed in Blackburn and Pierson (1994) and Ludwig et al. (2005).

Conclusions about grazing effects on dynamic soil properties are confounded by the heterogeneity of soil morphological properties, particularly in investigations conducted at spatial scales appropriate to livestock management (Stohlgren et al. 1999). Although this kind of variability is often difficult to deal with in experimental settings, it can provide the basis for a classification of spatial environmental variability. Incorporating spatial environmental variability into the design and analysis of ecological experiments can help refine interpretations about ecological processes (Dutilleul 1993; Herrick and Whitford 1995). Researchers working at landscape scales frequently use existing soil map units and their associated ecological site descriptions as a basis for stratifying sampling and data analysis (e.g., Miller 2008). However, soil maps in rangelands were created for purposes of management across large areas, and may not provide information at a scale useful for research applications, especially where soil heterogeneity is high at fine spatial scales. In such circumstances, researchers can develop a more customized means of obtaining soil morphological data that enables the incorporation of soil heterogeneity into sampling designs or statistical models.

In a grazing experiment on a temperate, semi-arid bunchgrass prairie, we measured the effects of cattle stocking rates on penetration resistance, soil aggregate stability, bare ground, and litter cover. We used a study-specific classification of sampling sites based on soil morphologic properties to evaluate the influence of inherent soil properties as a factor that is both separate from and interacts with effects of stocking rates on dynamic soil conditions. Our objectives were to 1) evaluate short-term sensitivity of dynamic soil properties to limitedduration grazing across a variety of stocking rates and 2) determine the degree to which inherent soil morphologic properties influence soil response to grazing. We predicted that higher grazing intensities would increase bare ground and penetration resistance and decrease litter cover and aggregate stability. We also predicted the response of dynamic soil properties would vary significantly with inherent soil morphological properties.

\section{METHODS}

\section{Study Area and Experimental Design}

Our study was part of a larger investigation of effects of livestock grazing on multiple components of the terrestrial food web. We conducted our study at the Zumwalt Prairie Preserve (lat $45^{\circ} 34^{\prime} \mathrm{N}$, long $116^{\circ} 58^{\prime} \mathrm{W}$ ) - a 13300 -ha property owned by The Nature Conservancy in northeastern Oregon. The study area encompassed 640 ha of high-elevation (1360-1500 m), temperate, semi-arid, Pacific Northwest Bunchgrass Prairie (for a detailed description of the study area, see Bartuszevige et al. 2012). Aboveground plant productivity, measured in 2006, averaged $1257 \mathrm{~kg} \cdot \mathrm{ha}^{-1}$ (Darambazar et al. 2007). Average monthly air temperatures range from $-3^{\circ} \mathrm{C}$ in January to $17^{\circ} \mathrm{C}$ in July; average annual precipitation is $351 \mathrm{~mm}$ (7-yr averages, The Nature Conservancy 2012). The study area received moderate to high levels of cattle grazing for several decades prior to the study and was rested completely from livestock grazing for $2 \mathrm{yr}$ before the beginning of our study in 2007. Soils across the study area have formed in basalt bedrock, loess, and colluvium; most soils are classified as Xerolls (Soil Survey Staff 2010). Microtopography and variable loess thickness have profoundly influenced soil formation and morphology, resulting in intricate patterns of contrasting soils that support a complex mosaic of plant assemblages.

The study was a randomized complete block design with one factor (cattle grazing) at four treatment levels (stocking rates) replicated four times (blocks), resulting in 16 experimental units (paddocks; Fig. 1A). Each paddock was $640 \mathrm{~m}^{2}$ (40 ha) and there were 36 sample sites within each paddock (144 per block; Fig. 1B) arranged as a grid with $90 \mathrm{~m}$ between sites. Measurements were taken at each sample site as described later in this article (Fig. 1C). The four stocking rates were: control (no 
A)
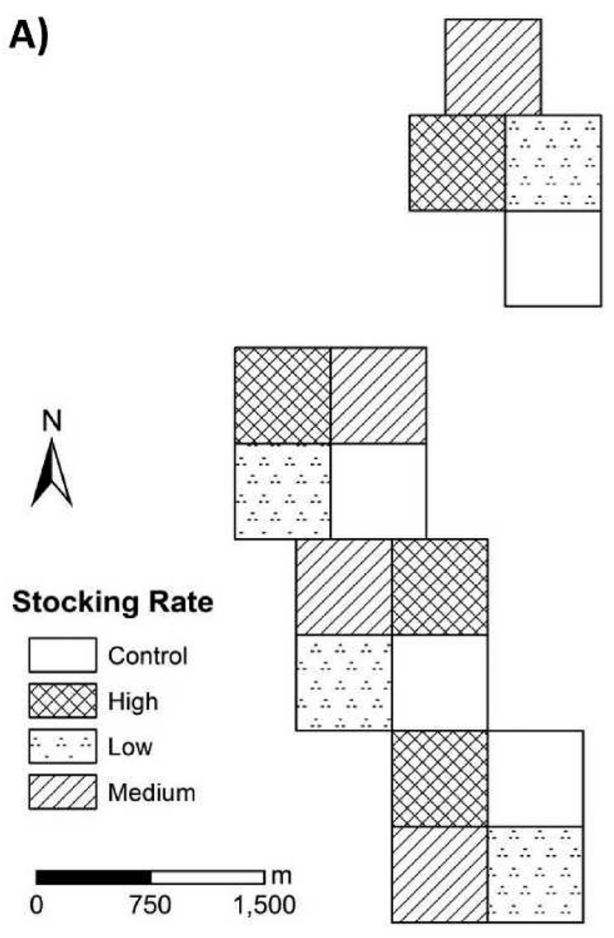

C)

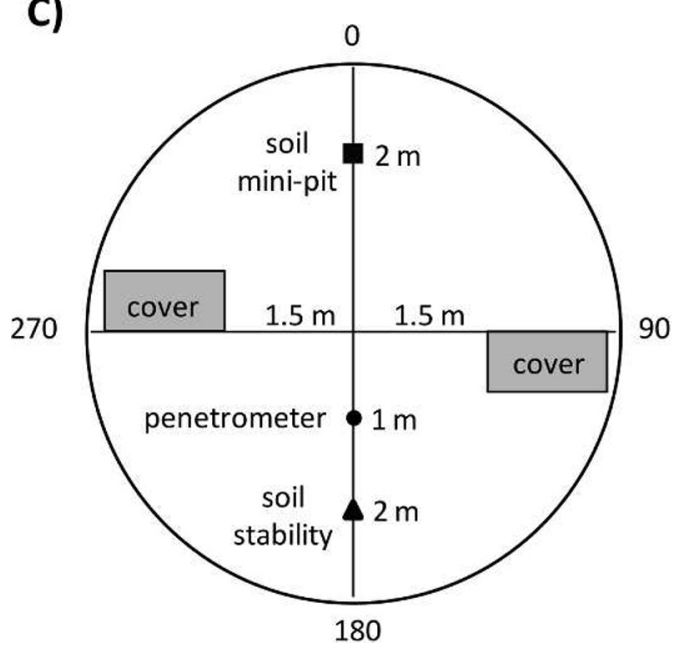

B)

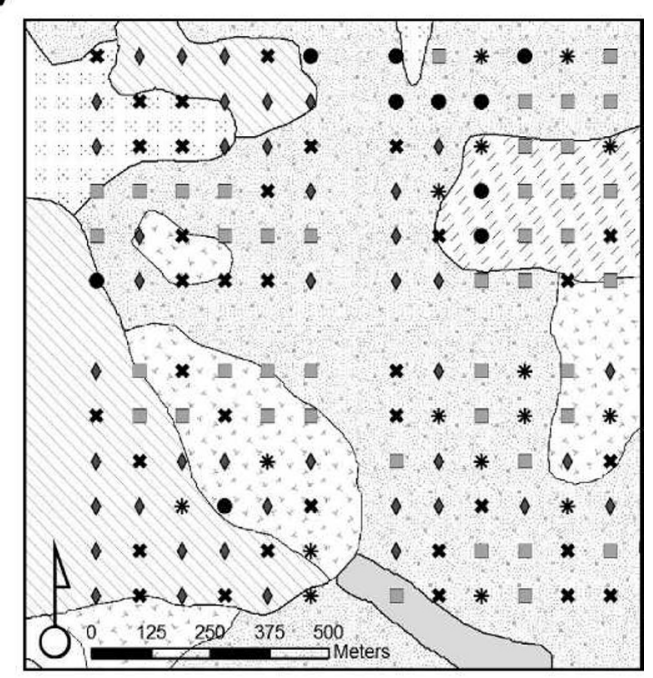

Soil Map Unit

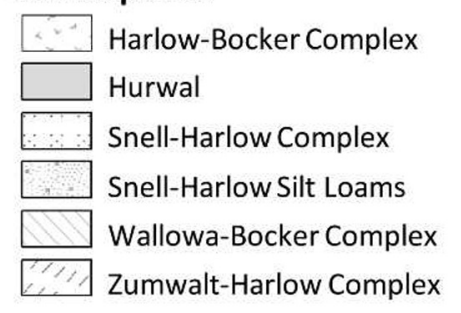

\section{Edaphic Habitat Type}

- Clay

$\square$ Moderately Deep Silty

* Shallow Silty

* Shallow Rocky

$\diamond$ Very Shallow Rocky

Figure 1. A, Layout of the study paddocks, illustrating the randomized complete block design with four stocking rates and four replicates. B, Layout of sample sites within one block of the study paddocks, showing the Edaphic Habitat Type classification of each sample site along with soil map unit polygons from the Soil Survey of the Wallowa County Area, Oregon (Soil Survey Staff 2010). C, Locations of sampling at a sample site. Stocking rates are animal unit months $\cdot \mathrm{ha}^{-1}$ : Control (0), Low (0.52), Medium (1.04), and High (1.56). Sample sites were 90 m apart and each paddock was 40 ha.

grazing by domestic livestock), low (0.52 animal unit month$\left.\mathrm{s} \cdot \mathrm{ha}^{-1}\right)$, medium (1.04 animal unit months $\left.\cdot \mathrm{ha}^{-1}\right)$, and high (1.56 animal unit months $\cdot \mathrm{ha}^{-1}$ ). To implement grazing treatments, 192 cow-calf pairs and 48 yearling heifers were randomly assigned to experimental units. Cattle grazed for 42 consecutive days from late May to early July in 2007 and 2008 and were then removed from paddocks. The medium stocking rate was chosen to simulate stocking rates used by area ranchers $(40 \%$ forage removal; T. DelCurto and J. Williams, unpublished results) and adjusted downward and upward by 50\% to achieve low and high stocking rates. Utilization was estimated at every sample site within a week of cattle removal. Observers visually estimated utilization categorically at each site as $0 \%, 1-25 \%$,
26-50\%, 51-75\%, or 76-100\%. Prior to estimating, observers were trained using simulated plots, from which observer-specific regression equations were developed to correct bias. Utilization estimates for the three stocking rates, averaged over the $2 \mathrm{yr}$ of the study were: low $20 \% \pm 1.1$ standard error (SE); medium $32 \% \pm 1.4 \mathrm{SE}$; and high $46 \% \pm 1.5 \mathrm{SE}$ (Wyffels 2009). Fencing did not exclude other herbivores, such as wild ungulates, small mammals, and herbivorous invertebrates; utilization estimated in controls was $9.5 \% \pm 0.5 \mathrm{SE}$, presumably a consequence of native herbivore grazing, primarily elk (Cervus elaphus; Wyffels 2009).

Although soil maps exist for the study area (Soil Survey Staff 2010), most of the map units are complexes, with significant 
variation occurring within one map unit. Initial field investigation of the soil map units determined that they would not be sufficient for capturing the environmental variability within the scale of the study paddocks (see Fig. 1B). Therefore, we devised our own method for classifying the soil morphological properties at each sample site. Our classification of soil properties introduced a second factor in the study design, which we called Edaphic Habitat Types (EHTs; described later in this article). EHT categories were treated posthoc as a splitplot within stocking rates, not paddocks because not all EHTs were present in all paddocks. An example of spatial distribution of EHT classifications across one of the study blocks is given in Figure 1B.

\section{Sampling Methods}

Dynamic Soil Properties. Measurement locations were situated in the same position at each sample site, and took place within a 5 -m radius circle centered on a permanent site marker (Fig. 1C). Because soil moisture affects the strength of bonding between soil particles and can introduce error into measures of compaction and stability, penetration resistance and soil stability were measured during the period of seasonal drought (approximately late July to early October). Soil moisture measured during sampling periods was $<20 \%$ by weight to a depth of $20 \mathrm{~cm}$. Pretreatment data for penetration resistance and soil stability were collected from July to October in 2006; posttreatment data were collected in August 2008, shortly after cattle were removed. Bare ground and herbaceous litter were assessed between late May and early August when plant canopies were fully developed; pretreatment data were collected in 2006 and posttreatment data were collected in 2009; in both years no cattle were present.

Soil resistance to penetration was measured with a dynamic cone penetrometer (Herrick and Jones 2002). The penetrometer had a 2-kg weight that was released from a height of $60 \mathrm{~cm}$ repeatedly until the instrument tip had penetrated a depth of 20 $\mathrm{cm}$ or was impeded by rock fragments. Sites at which maximum depth in either of the two measurement years was $<10 \mathrm{~cm}$ were omitted from analysis, as recommended by Herrick (2005). Data are expressed in $\mathrm{J} \cdot \mathrm{cm}^{-1}$ averaged over total depth penetrated.

Soil stability was measured in the field at two depths (0-3 $\mathrm{mm}$ and 3-6 $\mathrm{mm}$ ) using a modified slake test (Herrick et al. 2001), which is a visual estimation of how readily a small soil sample falls apart when submersed in water. The soil sample was placed on a sieve with $1.5-\mathrm{mm}$ openings and set into water for $5 \mathrm{~min}$ followed by five gentle dipping cycles. Structural response of samples was recorded on an interval scale of 1-6, according to the following criteria: 1) $50 \%$ of structural integrity lost within $5 \mathrm{~s}$ of immersion in water; 2) $50 \%$ of structural integrity lost 5-30 s after immersion; 3) $50 \%$ of structural integrity lost 30-300 s after immersion or $<10 \%$ of soil remains on sieve after five dipping cycles; 4) $10-25 \%$ of soil remains on sieve after five dipping cycles; 5) $25-75 \%$ of soil remains on sieve after five dipping cycles; and 6) 75-100\% of soil remains on sieve after five dipping cycles. If rock fragments were encountered at the sampling location, observers searched for the nearest location $(\leq 10 \mathrm{~cm})$ where a rock-free sample could be obtained. If a sample could still not be obtained, these sample sites were recorded as rock and were not included in data analysis. This occurred for $<2.5 \%$ of sample sites.

Bare ground and herbaceous litter were estimated visually in two $1 \times 0.5 \mathrm{~m}$ quadrats at each sample site. Cover classes were established according to the following percentage categories: $0 \%,<1 \%, 1-<5 \%, 5-<25 \%, 25-<50 \%, 50-<75 \%, 75-$ $<95 \%, 95-<99 \%$, and $99-100 \%$. Bare ground was defined as any soil surface area where a drop of rain would contact the soil unimpeded by plant canopy, litter cover, soil crusts, or rock fragments (Herrick et al. 2005). Herbaceous litter was defined as detached dead stems and leaves that are part of a layer that comes in contact with the ground and does not include woody material (Herrick et al. 2005). Cover class data were converted to midpoints of each class and averaged for each sample site prior to analysis.

Soil Characterization. At the onset of the study, soil morphologic characteristics were observed at each sample site by digging a small pit to a depth of $\sim 25 \mathrm{~cm}$ or shallower if bedrock was encountered. Soil depth was measured as the maximum depth of the pit if $<25 \mathrm{~cm}$ or by using a steel rod driven into the soil beyond the depth of the pit. If rocks were encountered with the rod, multiple attempts were made until the rod went into soil or encountered impervious rock fragments. Soil depth was categorized as $<25 \mathrm{~cm}, 25-50 \mathrm{~cm}$ or $>50 \mathrm{~cm}$; texture was determined using the "texture by feel method" (Schoeneberger et al. 2002). Rock fragment content was assigned a category based on ocular estimation of rock fragments visible in the exposed profile: $<15 \%, 15-30 \%$, or $>30 \%$. Although field observations lack the precision and accuracy of laboratory analysis, when performed consistently by a single person trained in the techniques (as was the case in our study), they provide adequate measures for comparative categorization. Categorical field observations of soil depth, texture, and percentage rock fragments were used to classify each sample site as one of five EHTs: Moderately Deep Silty (M/Silty); Shallow Silty (S/Silty); Shallow Rocky (S/Rocky); Clay; and Very Shallow Rocky (VS/Rocky; Table 1).

\section{Data Analysis}

For all measurements, individual sample sites (576) were treated as subsamples within each unique combination of block, stocking rate, and EHT, for a total of 80 possible samples. To ensure that EHT classification of each sample site was describing a homogeneous condition across the 5-m radius sample site, we omitted 47 sample sites a priori that had gross discrepancies between the soil pit location and the other soil or vegetation sampling locations. Omitting these subsamples reduced total possible sample number to 75 . Sample sizes for hypothesis testing depended on the factor being tested. In testing for effects of stocking rate on herbaceous litter, bare ground, and soil stability, $n=4$; for testing effects of EHT classes, $n=5$. Soil penetration resistance could not be measured adequately in soils that were rocky (the S/Rocky and VS/Rocky EHTs); therefore, statistical tests of EHT effects on penetration resistance were performed using values from only three of the EHTs. All data used in analyses met assumptions of normality and homogeneity of variances, except for posttreatment subsurface soil stability, which was slightly skewed. We used untransformed data because 
Table 1. Soil morphologic properties associated with Edaphic Habitat Type classification.

\begin{tabular}{lclll}
\hline Edaphic Habitat Type & Depth & & Texture & Rock content \\
\hline M/Silty & & & \\
Clay & $\geq 50 \mathrm{~cm}$ & Silt Loam or Silty Clay Loam & $<15 \%{ }^{2}$ \\
S/Silty & $<25 \mathrm{~cm}$ to $\geq 50 \mathrm{~cm}$ & Clay or Silty Clay throughout or abrupt Bt horizon (subsurface clay accumulation) & $<15 \%$ to $>30 \%$ \\
S/Rocky & $25-49 \mathrm{~cm}$ & Silt Loam or Silty Clay Loam & $<15 \%$ \\
VS/Rocky & $25-49 \mathrm{~cm}$ & Silt Loam, Silty Clay Loam, Clay Loam, Silty Clay, Loam, Sandy Loam & $>15 \%$ \\
\hline
\end{tabular}

${ }^{1} \mathrm{M}$ indicates moderately deep; S, shallow; VS, very shallow.

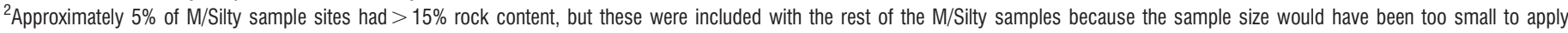
statistical methods.

analysis of variance has been shown to be robust to departures from normality (Glass et al. 1972).

Mixed effects models were used to evaluate fixed effects of stocking rate, EHT, and stocking rate $\times \mathrm{EHT}$ separately for posttreatment and pretreatment data. Block and block $\times$ stocking rate were random effects. The blocking factor was variation in historical grazing management. Time was not included in the statistical model; therefore, pretreatment results are presented only for stocking rate effects for the purpose of assessing pretreatment conditions across the study area. Data were modeled using PROC MIXED in SAS System version 9.3.1 (SAS Institute Inc, 2002-2003). Significant differences between stocking rates and EHT classes were assessed using pair-wise comparisons of least squares means with a Tukey-Kramer adjustment for multiple comparisons. In the case of a significant interaction between the two main factors, effects of stocking rate were evaluated separately for each EHT in a posthoc analysis of variance. An alpha level of $\leq 0.05$ was considered statistically significant.

\section{RESULTS}

Pretreatment data showed no significant differences between stocking rates for herbaceous litter $\left(\mathrm{F}_{3,9}=0.41, P=0.75\right)$, bare ground $\left(\mathrm{F}_{3,9}=0.47, P=0.71\right)$, or soil stability (surface: $\mathrm{F}_{3,9}=0.74, P=0.56$; subsurface: $\mathrm{F}_{3,9}=0.1 .27, P=0.34$; data not shown). Pretreatment penetration resistance was different between stocking rates $\left(\mathrm{F}_{3,9}=4.43, P=0.04\right.$; Fig. 2$)$; however, the only difference was higher penetration resistance in the low stocking rate paddocks than in the control paddocks.

The analysis of posttreatment data showed that stocking rate had a significant effect on penetration resistance $\left(\mathrm{F}_{3,9}=10.77\right.$, $P<0.01$ ) where penetration resistance was highest with high stocking rates and lowest with no grazing of domestic livestock (Fig. 3A). There was no statistically significant effect of stocking rate on bare ground $\left(\mathrm{F}_{3,9}=2.85, P=0.10\right.$; Fig. $\left.3 \mathrm{~B}\right)$ or soil stability at either depth (surface: $\mathrm{F}_{3,9}=2.12, P=0.17$; subsurface: $\mathrm{F}_{3,9}=1.61, P=0.25$; Fig. $3 \mathrm{C}$ ). The effect of stocking rate on herbaceous litter depended on EHT $\left(\mathrm{F}_{12,43}=2.06\right.$, $P=0.04)$, with significant effects of stocking rate expressed in the M/Silty, S/Rocky, and VS/Rocky EHTs. In the M/Silty EHT, litter cover was lower in the high stocking rate than in the control or low stocking rate $\left(\mathrm{F}_{3,9}=4.37, P=0.04\right.$; Fig. 4$)$. In the S/Rocky and VS/Rocky EHTs, the control generally had significantly more litter than low, moderate, or high stocking rates $\left(\mathrm{F}_{3,9}=5.53, P=0.02 ; \mathrm{F}_{3,6}=22.85 P<0.01\right.$, respectively; Fig. 4). There were no interactions between stocking rate and
EHT for penetration resistance $\left(\mathrm{F}_{6,23}=0.35, P=0.91\right)$, bare ground $\left(\mathrm{F}_{12,43}=1.14, P=0.36\right)$, or soil stability (surface: $\mathrm{F}_{12,43}=1.58, P=0.13$; subsurface: $\mathrm{F}_{12,43}=1.71, P=0.10$ ).

The M/Silty EHT was predominant across the study area (36\% of sites), followed by Clay (19\%), S/Rocky (17\%), VS/ Rocky $(16 \%)$, and S/Silty (12\%). Proportions of EHTs across stocking rates were fairly even (Fig. 5). For posttreatment measurements, penetration resistance was lower in the M/Silty EHT than in the S/Silty or Clay EHTs $\left(\mathrm{F}_{4,23}=9.36, P<0.01\right.$; Fig. 6A). Bare ground was lowest in the M/Silty EHT and highest in the Clay, S/Rocky, and VS/Rocky EHTs $\left(\mathrm{F}_{4,43}=8.1\right.$, $P<0.01$; Fig. 6B). Surface soil stability was highest in the M/ Silty and S/Silty EHTs and lowest in the VS/Rocky EHT $\left(\mathrm{F}_{4,43}=18.86, P<0.01\right.$; Fig. $\left.6 \mathrm{C}\right)$; subsurface soil stability was lowest in the VS/Rocky EHT $\left(\mathrm{F}_{4,43}=10.59, P<0.01\right.$; Fig. $\left.6 \mathrm{C}\right)$.

\section{DISCUSSION}

As part of sustainable grazing management, monitoring effects of grazing on dynamic soil properties can provide important

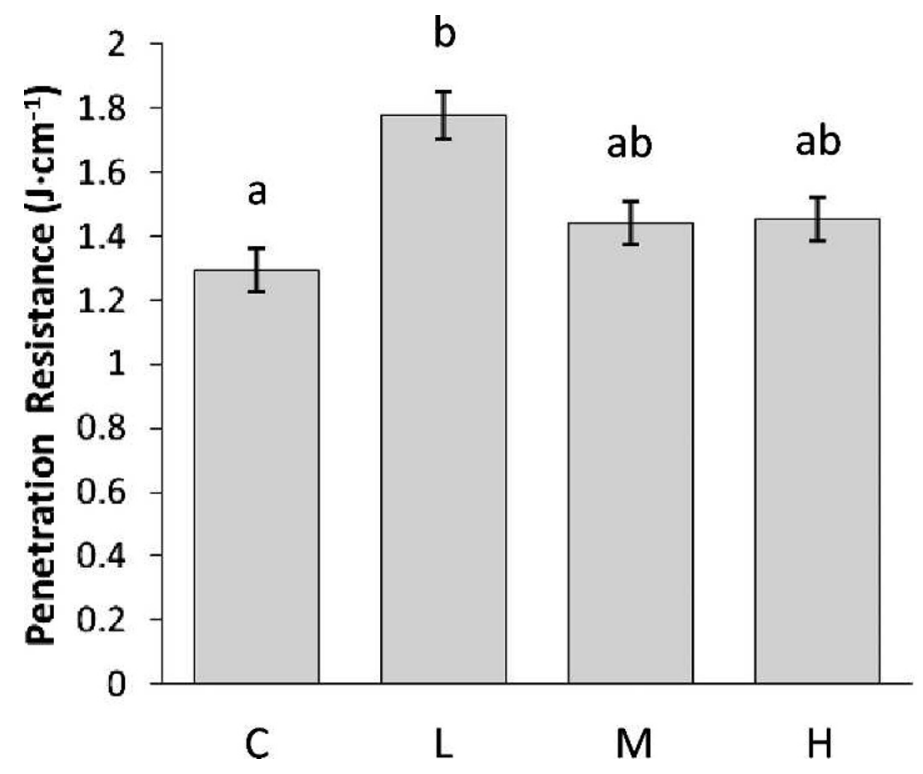

Figure 2. Least square means and differences between stocking rates for pretreatment measures of penetration resistance. Stocking rates are animal unit months $\cdot$ ha $^{-1}$ : Control (C; 0), Low (L; 0.52), Medium (M; 1.04), and High $(H ; 1.56)$. All error bars are one standard error of the mean. Bars that share a letter are not significantly different at $\alpha=0.05$ with the TukeyKramer method for multiple pairwise comparisons. 

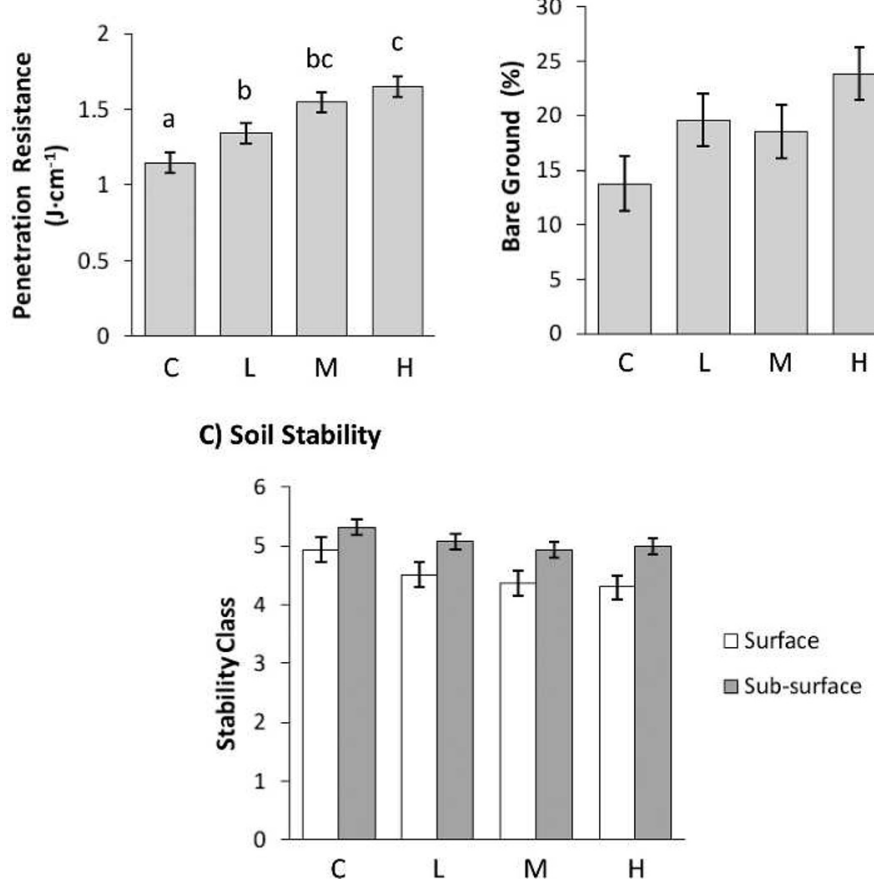

Figure 3. Least square means and differences between stocking rates for posttreatment measures of $\mathbf{A}$, penetration resistance; $\mathbf{B}$, bare ground; and C, soil stability. Stocking rates are animal unit months $\cdot$ ha $^{-1}$ : Control $(C ; 0)$, Low (L; 0.52), Medium (M; 1.04), and High ( $\mathrm{H} ; 1.56)$. For soil stability, light bars are surface $(0-3 \mathrm{~mm})$ and dark bars are subsurface $(3-6 \mathrm{~mm})$ responses. All error bars are one standard error of the mean. Bars that share a letter are not significantly different at $\alpha=0.05$ with the TukeyKramer method for multiple pairwise comparisons.

information for range managers and livestock producers. Our evaluation of short-term responses of dynamic soil properties showed that penetration resistance and herbaceous litter cover were affected by cattle stocking rates. In our study, penetration resistance increased with stocking rate, which has been demonstrated in other studies. Chanasyk and Naeth (1995) measured significantly higher penetration resistance in heavily grazed treatments (even for short, 1-wk durations) in fescue grasslands in Alberta. In semi-arid temperate grasslands in Argentina, controls ungrazed for $>30 \mathrm{yr}$ had significantly lower penetration resistance than areas under moderate or intense grazing (Villamil et al. 2001). Teague et al. (2011) also found significantly lower penetration resistance in ungrazed controls than under light and heavy continuous grazing management but not under multipaddock rotational grazing management in the tall grass prairie of Texas. Thus, our results support previous findings and demonstrate penetration resistance increases with stocking rates in Pacific Northwest Bunchgrass Prairie ecosystems even in the short term and warrants careful monitoring to guide management prescriptions.

Herbaceous litter cover was affected by both stocking rate and EHT. In two of the EHTs-S/Silty and Clay-litter cover was similar across all levels of stocking rate; however, in the other three EHTs, stocking rates generally decreased litter cover. This complex relationship between EHT and stocking

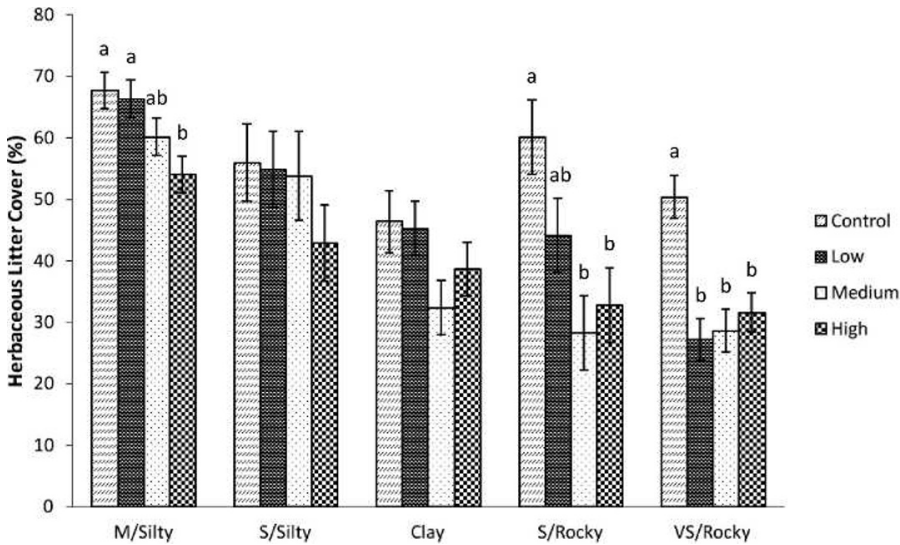

Figure 4. Least square means and differences between stocking rates for posttreatment herbaceous litter cover, by Edaphic Habitat Type. Abbreviations are: $\mathrm{M}=$ Moderately Deep; $\mathrm{S}=$ Shallow; and $\mathrm{VS}=$ Very Shallow. Stocking rates are animal unit months $\cdot \mathrm{ha}^{-1}$ : Control (0), Low (0.52), Medium (1.04), and High (1.56). All error bars are one standard error of the mean. Bars that share a letter are not significantly different at $\alpha=0.05$ with the Tukey-Kramer method for multiple pairwise comparisons.

rate suggests that the effects of stocking rate on litter increased with rockiness and decreased with soil depth. In general, litter amounts are determined by total aboveground biomass, and aboveground biomass is strongly influenced by the soil's capacity to support vegetative growth. In our study area, analysis of pretreatment data showed a strong relationship between total aboveground biomass and EHT, with greatest biomass in the M/Silty EHT and lowest biomass in the VS/ Rocky EHT (Schmalz 2011). Thus, it is not surprising that litter cover in the controls alone appeared to increase with soil depth. In addition, soil depth has been shown to interact with grazing as a driver of changes in patterns of plant communities (Fuhlendorf and Smeins 1998). Overall, our results suggest that greater litter cover, which is associated with deeper, less rocky soils, may buffer effects of low to moderate stocking rates.

Soil aggregate stability and bare ground did not respond significantly to short-term effects of cattle stocking rates. Evidence from grazing studies on similar grasslands has shown that bare ground increases with higher stocking rates (Naeth et al. 1991; Hart and Frasier 2003; Teague et al. 2011) and that aggregate stability decreases with higher stocking rates (Greenwood and McKenzie 2001). The lack of significant responses to stocking rates in our study may be due to the type and condition of our bunchgrass prairie, as well as the short duration of grazing ( $84 \mathrm{~d}$ total for the $2 \mathrm{yr}$ ). Our study site is a moderately productive semi-arid grassland with generally high aggregate stability and low proportions of bare ground despite decades of grazing at moderate levels prior to the study period. It is likely that ecological processes such as root growth and decomposition, maintenance of soil organic matter and microorganisms, and nutrient cycling are proceeding at rates sufficient to maintain high aggregate stability and low proportions of bare ground even with moderate levels of livestock grazing. It may take a longer duration of more intense grazing for these dynamic soil properties to respond significantly, if at all. For comparison, grazing effects on soil 


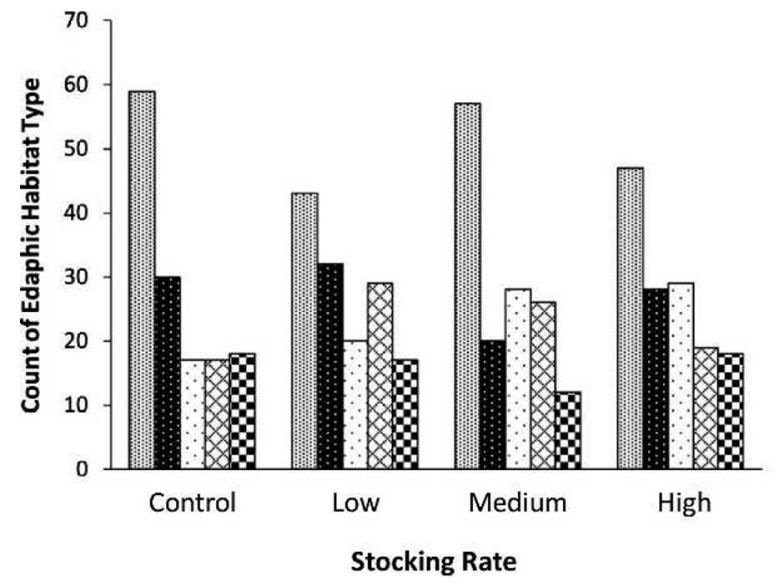

Figure 5. Distribution of Edaphic Habitat Types across stocking rates. Abbreviations are: $M=$ moderately deep $(>50 \mathrm{~cm}) ; \mathrm{S}=$ shallow $(25-50$ $\mathrm{cm})$; and $\mathrm{VS}=$ very shallow $(<25 \mathrm{~cm})$. Rocky indicates $>15 \%$ rock fragments (by surface area of exposed soil profile).

aggregate stability in southern British Columbia were seen after $30 \mathrm{yr}$ but not after $20 \mathrm{yr}$ of moderate grazing (Evans et al. 2012).

The variability in soils across landscapes is a fundamental consideration in sampling designs for research and monitoring. The approach we used to account for soil differences using EHTs allowed us to evaluate the influence of EHTs separately from the influence of stocking rates. For herbaceous litter, this approach made it possible to determine which EHTs were affected by stocking rates and which were not. For penetration resistance, aggregate stability, and bare ground, the differences among EHTs alone demonstrated the variability that exists within standard landscape classification approaches, such as soil map units. While an intensive approach to categorizing soil properties may be desirable for research purposes, it may not be practical for general grazing monitoring. Nevertheless, it is important for grazing managers and rangeland practitioners to be aware of the variability contained within landscape classification units; this variability can mask grazing effects. Depending on the variable of interest and the type of landscape, other means of stratification may be appropriate, such as stratification of soil aggregate stability sampling by categories of vegetation cover (Herrick et al. 2001; Bestelmeyer et al. 2006).

Dynamic soil properties are often used as indicators of ecosystem function and complex physical processes. While measuring dynamic soil properties allows the assessment of point-in-time or trend conditions, this method does not directly measure processes, such as infiltration and runoff. One of the challenges to interpreting indicators is that the causality between indicators and physical processes are not always well-developed (Herrick 2000). For example, soil penetration resistance measured with the dynamic cone penetrometer is a relatively new method, and the values obtained with a dynamic penetrometer cannot be directly compared with those obtained using a static penetrometer (Herrick and Jones 2002), for which there are well-developed correlations with physical states and biophysical processes. Associations between dynamic penetrometer measurements and soil hydrologic processes have recently been explored and showed that penetration resistance

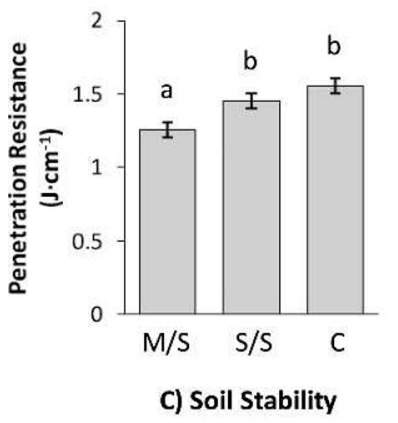

B) Bare Ground
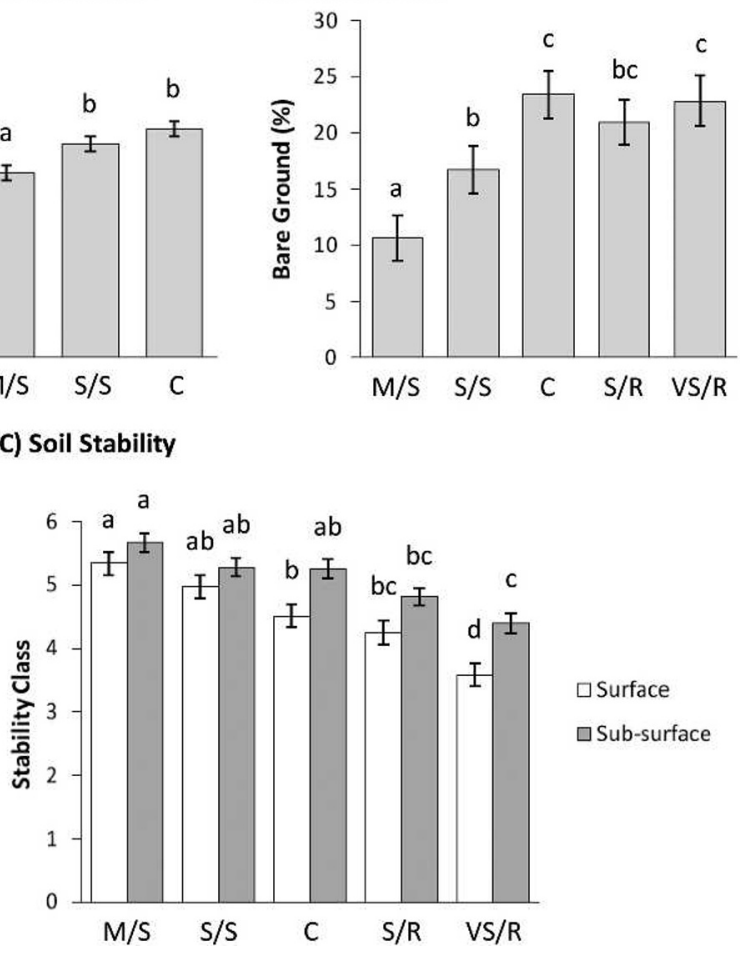

Figure 6. Least square means and differences between Edaphic Habitat Types for posttreatment measurements of $\mathbf{A}$, penetration resistance; $\mathbf{B}$, bare ground; and C, soil stability. Abbreviations are: $\mathrm{M} / \mathrm{S}=$ Moderately Deep Silty; $S / S=$ Shallow Silty; $C=$ Clay; $S / R=$ Shallow Rocky; and $V S / R=$ Very Shallow Rocky. For soil stability, light bars are surface $(0-3 \mathrm{~mm})$ and dark bars are subsurface (3-6 $\mathrm{mm}$ ) responses. All error bars are one standard error of the mean. Bars that share a letter are not significantly different at $\alpha=0.05$ with the Tukey-Kramer method for multiple pairwise comparisons.

was inversely related to infiltration and positively related to runoff and sediment yield (Teague et al. 2008, 2011). Modeling runoff and infiltration on rangelands is multivariate by nature (Spaeth et al. 1996), with correlations between any single indicator and a given physical process lacking continuity across the diverse landscapes that constitute rangelands. For example, in a comparison of 11 different range sites, five sites did not show strong correlations between litter cover and infiltration (Pierson et al. 2002). Continued research is needed across a variety of landscapes to confidently infer ecosystem processes or functions from indicators.

Methods for measuring dynamic soil properties are intended for use at pasture or ranch scales and are accessible to anyone, requiring minimal equipment and training. This is an advantage for practitioners who do not have the time, equipment, or need to embark on watershed-scale measurements of runoff and infiltration. The limitations of inferring ecosystem function from indicators must be acknowledged and interpretations must be made relative to inherent potential of the landscape and timing and duration of grazing. Interpretations are more meaningful when thresholds for ecosystem function and mechanisms of functional change (as suggested in Briske et al. 2006) are established for an area. In our study area, this information is not yet available. The fact that penetration resistance and herbaceous litter cover were significantly 
affected by short-term cattle grazing suggests that continued monitoring of these properties across different management strategies could, over time, guide managers' decisions about grazing plans. Measures of aggregate stability and bare ground should also be considered for long-term monitoring. Coupling these measurements with observations of ecosystem processes and functions in the future will aid efforts to model livestock effects on ecosystem processes and to determine what amount of change in dynamic soil properties leads to critical changes in ecosystem function.

\section{IMPLICATIONS}

Sustainable management goals for managing domestic livestock on uncultivated grasslands include maintaining vegetation cover and minimizing soil disturbance. This ensures the moisture retention and infiltration necessary for long-term productivity and soil conservation. In a semi-arid, temperate bunchgrass prairie, short-season stocking rates between 1.04 and 1.56 animal unit months $\cdot \mathrm{ha}^{-1}$ resulted in lower amounts of herbaceous litter cover in rocky soils and higher penetration resistance in nonrocky soils. Long-term grazing at these rates may result in conditions that compromise soil quality and plant productivity. We also found that litter cover response to stocking rate interacted with soil type. This suggests stratification of sampling by soil types may increase the likelihood of detecting effects of stocking rate treatments on litter cover. Easily measured dynamic soil properties can be a valuable tool for monitoring the response of grassland soils to various livestock grazing strategies. Measuring a combination of dynamic soil properties known to be associated with physical processes such as infiltration or moisture retention does not directly provide estimates of soil loss or runoff, but can provide meaningful information about the effects of livestock management relevant to such functions. The relevance of dynamic soil properties may vary across different landscapes, soil types, or vegetation patterns, and effective monitoring will depend on careful selection of dynamic properties and sampling design.

\section{ACKNOWLEDGMENTS}

The authors would like to acknowledge The Nature Conservancy for site access, infrastructure, and logistical support. Data for bare ground and herbaceous litter cover were collected by Sam Wyffels and Abe Clark of Oregon State University; special thanks to Sam Wyffels and Tim DelCurto of the Eastern Oregon Agricultural Research Center for sharing these data. Great appreciation is extended to the seasonal field crews at the Zumwalt Prairie Preserve for data collection and field work. Bill Price at the University of Idaho provided guidance for statistical analyses. Feedback from three anonymous reviewers improved this manuscript.

\section{LITERATURE CITED}

Barthes, B., and E. Roose. 2002. Aggregate stability as an indicator of soil susceptibility to runoff and erosion; validation at several levels. Catena 47:133149.

Bartuszevige, A. B., P. L. Kennedy, and R. V. Taylor. 2012. Sixty-seven years of landscape changes in the last, large remnant of the Pacific Northwest Bunchgrass Prairie. Natural Areas Journal 32:166-170.
Benkobi, L., M. J. Trlica, and J. L. Smith. 1993. Soil loss as affected by different combinations of surface litter and rock. Journal of Environmental Quality 22:657661.

Bestelmeyer, B. T., J. P. Ward, J. E. Herrick, and A. J. Tugel. 2006. Fragmentation effects on soil aggregate stability in a patchy arid grassland. Rangeland Ecology \& Management 59:406-415.

Blackburn, W. H., and F. B. Pierson, JR. 1994. Sources of variation in interrill erosion on rangelands. In: W. H. Blackburn, J. F. B. Pierson, G. E. Shuman, and R. Zartman [EDS.]. Variability in rangeland water erosion processes. Madison, WI, USA: Soil Science Society of America. p. 1-10.

BoEkEN, B., AND D. ORENSteIn. 2001. The effect of plant litter on ecosystem properties in a Mediterranean semi-arid shrubland. Journal of Vegetation Science 12:825-832.

BreCKenRIDGE, R. P. 1994. A process for selecting indicators for monitoring conditions of rangeland health. Environmental Monitoring and Assessment 36:45-60.

Briske, D. D., S. D. Fuhlendorf, and F. E. Smeins. 2006. A unified framework for assessment and application of ecological thresholds. Rangeland Ecology \& Management 59:225-236.

Chanasyk, D. S., and M. A. Naeth. 1995. Grazing impacts on bulk density and soil strength in the foothills fescue grasslands of Alberta, Canada. Canadian Journal of Soil Science 75:551-557.

Charter, M. P., C. M. Rostagno, and G. E. Pazos. 2011. Effects of soil degradation on infiltration rates in grazed semiarid rangelands of northeastern Patagonia, Argentina. Journal of Arid Environments 75:656-661.

Chen, G. H., And R. R. Well. 2010. Penetration of cover crop roots through compacted soils. Plant and Soil 331:31-43.

Daniel, J. A., K. Potter, W. Altom, H. Aluoe, and R. Stevens. 2002. Long-term grazing density impacts on soil compaction. Transactions of the American Society of Agricultural Engineers 45:1911-1915.

Darambazar, E., T. DelCurto, D. Damiran, A. Clark, and R. Taylor. 2007. Species composition and diversity on Northwestern bunchgrass prairie rangelands. Faculty Research Publications. Union, OR, USA: Eastern Oregon Agricultural Research Center. 14 p.

Dormaar, J. F., and W. D. Willms. 1998. Effect of forty-four years of grazing on fescue grassland soils. Journal of Range Management 51:122-126.

Dunn, B. H., A. J. Smart, R. N. Gates, P. S. Johnson, M. K. Beutler, M. A. Diersen, and L. L. JANSSEN. 2010. Long-term production and profitability from grazing cattle in the Northern mixed grass prairie. Rangeland Ecology \& Management 63:233-242.

Dutilleul, P. 1993. Spatial heterogeneity and the design of ecological field experiments. Ecology 74:1646-1658.

Evans, C. R. W., M. KrzIC, K. Broersma, and D. J. Thompson. 2012. Long-term grazing effects on grassland soil properties in southern British Columbia. Canadian Journal of Soil Science 92:685-693.

Fernandez, D. P., J. C. Neff, and R. L. Reynolds. 2008. Biogeochemical and ecological impacts of livestock grazing in semi-arid southeastern Utah, USA. Journal of Arid Environments 72:777-791.

Fuhlendorf, S. D., And F. E. Smeins. 1998. The influence of soil depth on plant species response to grazing within a semi-arid savanna. Plant Ecology 138:89-96.

GIFFORD, G. F., AND R. H. Hawkins. 1978. Hydrologic impact of grazing on infiltration: a critical review. Water Resources Research 14:305-313.

Glass, G. V., P. D. Peckham, And J. R. Sanders. 1972. Consequences of failure to meet assumptions underlying fixed effects analyses of variance and covariance. Review of Educational Research 42:237-288.

Greenwood, K. L., D. A. MacLeod, and K. J. Hutchinson. 1997. Long-term stocking rate effects on soil physical properties. Australian Journal of Experimental Agriculture 37:413-419.

Greenwood, K. L., And B. M. McKenzle. 2001. Grazing effects on soil physical properties and the consequences for pastures: a review. Australian Journal of Experimental Agriculture 41:1231-1250.

HART, R. H., AND G. W. FraSIER. 2003. Bare ground and litter as estimators of runoff on short- and mixed-grass prairie. Arid Land Research and Management 17:485490.

HerRick, J. E. 2000. Soil quality: an indicator of sustainable land management? Applied Soil Ecology 15:75-83.

Herrick, J. E., J. R. Brown, A. J. Tugel, P. L. Shaver, and K. M. Havstad. 2002. Application of soil quality to monitoring and management: paradigms from rangeland ecology. Agronomy Journal 94:3-11. 
HerRick, J. E., And T. L. Jones. 2002. A dynamic cone penetrometer for measuring soil penetration resistance. Soil Science Society of America Journal 66:1320-1324.

Herrick, J. E., J. W. VanZee, K. M. Havstad, L. M. Burkett, and W. G. Whitford. 2005. Monitoring manual for grassland, shrubland, and savanna ecosystems. Volume I: quick start. Las Cruces, NM, USA: USDA-ARS Jordana Experimental Range. $36 \mathrm{p}$.

HerRick, J. E., AND W. G. Whitford. 1995. Assessing the quality of rangeland soils:challenges and opportunities. Journal of Soil and Water Conservation 50:237-242.

Herrick, J. E., W. G. Whitford, A. G. de Soyza, J. W. Van Zee, K. M. Havstad, C. A. SEYBoLd, AND M. WALton. 2001. Field soil aggregate stability kit for soil quality and rangeland health evaluations. Catena 44:27-35.

Holechek, J. L., R. D. Pieper, and C. H. Herbel. 1995. Range management principles and practices. Upper Saddle River, NJ, USA: Prentice Hall. 526 p.

Jastrow, J. D., R. M. Mlller, and J. Lussenhop. 1998. Contributions of interacting biological mechanisms to soil aggregate stabilization in restored prairie. Soil Biology \& Biochemistry 30:905-916.

Ludwig, J. A., B. P. Wilcox, D. D. Breshears, D. J. Tongway, and A. C. Imeson. 2005. Vegetation patches and runoff-erosion as interacting ecohydrological processes in semiarid landscapes. Ecology 86:288-297.

MilleR, M. E. 2008. Broad-scale assessment of rangeland health, Grand StaircaseEscalante National Monument, USA. Rangeland Ecology \& Management 61:249262.

MitcheLL, J. E. [ED.] 2010. Criteria and indicators of sustainable rangeland management. Laramie, WY, USA: University of Wyoming Extension. Publication No. SM-56. 227 p.

Naeth, M. A., A. W. Balley, D. J. Pluth, D. S. Chanasyk, and R. T. Hardin. 1991. Grazing impacts on litter and soil organic matter in mixed prairie and fescue grassland ecosystems of Alberta. Journal of Range Management 44:7-12.

Naeth, M. A., and D. S. Chanasyk. 1995. Grazing effects on soil-water in Alberta foothills fescue grasslands. Journal of Range Management 48:528-534.

National Research Council. 1994. Rangeland health: new methods to classify, inventory, and monitor rangelands. Washington, DC, USA: National Academy Press. $180 \mathrm{p}$.

Northup, B. K., J. R. Brown, and A. J. Ash. 2005. Grazing impacts on spatial distribution of soil and herbaceous characteristics in an Australian tropical woodland. Agroforestry Systems 65:137-150.

Pierson, F. B., K. E. Spaeth, M. A. Weltz, and D. H. Carlson. 2002. Hydrologic response of diverse western rangelands. Journal of Range Management 55:558-570.

Pietola, L., R. Horn, and M. Yli-Halla. 2005. Effects of trampling by cattle on the hydraulic and mechanical properties of soil. Soil \& Tillage Research 82:99-108.

Pyke, D. A., And J. E. HerRICK. 2003. Transitions in rangeland evaluations: a review of the major transitions in rangeland evaluations during the last 25 years and speculation about future evaluations. Rangelands 25(6):22-30.

Pyke, D. A., J. E. Herrick, P. Shaver, and M. Pellant. 2002. Rangeland health attributes and indicators for qualitative assessment. Journal of Range Management 55:584-597.

ScHMALZ, H. 2011. Soil spatial heterogeneity and measured soil responses: factors in an ecological grazing experiment on a bunchgrass prairie [thesis]. Moscow, ID, USA: University of Idaho. $128 \mathrm{p}$.

Schoeneberger, P. J., D. A. Wysocki, E. C. Benham, and W. D. Broderson [eds.]. 2002. Field book for describing and sampling soils, version 2.0. Lincoln, NE, USA: USDA-NRCS National Soil Survey Center. 228 p.

Sheley, R. L., J. J. James, E. A. VAsquez, and T. J. Svejcar. 2011. Using rangeland health assessment to inform successional management. Invasive Plant Science and Management 4:356-367.

Smets, T., J. Poesen, and E. Bochet. 2008. Impact of plot length on the effectiveness of different soil-surface covers in reducing runoff and soil loss by water. Progress in Physical Geography 32:654-677.
Smith, E. L., P. S. Johnson, G. Ruyle, F. Smeins, D. Loper, D. Whetsell, D. Child, P. Sims, R. Smith, L. Volland, M. Hemstrom, E. Bainter, A. Mendenhall, K. Wadman, D. Franzen, M. Suthers, J. Willoughby, N. Habich, T. Gaven, and J. Haley. 1995. New concepts for assessment of rangeland condition. Journal of Range Management 48:271-282.

Soll SuRvey Staff. 2010. Web soil survey, Wallowa County. Available at: http:// websoilsurvey.nrcs.usda.gov. Accessed 13 March 2010.

Spaeth, K. E., F. B. Pierson, M. A. Weltz, and J. B. Awang. 1996. Gradient analysis of infiltration and environmental variables as related to rangeland vegetation. Transactions of the American Society of Agricultural Engineers 39:67-77.

Stohlgren, T. J., L. D. Schell, and B. Vanden Heuvel. 1999. How grazing and soil quality affect native and exotic plant diversity in rocky mountain grasslands. Ecological Applications 9:45-64.

Teague, W. R., S. L. Dowhower, S. A. Baker, N. Halle, P. B. Delaune, and D. M. Conover. 2011. Grazing management impacts on vegetation, soil biota and soil chemical, physical and hydrological properties in tall grass prairie. Agriculture Ecosystems \& Environment 141:310-322.

Teague, W. R., S. E. Duke, J. A. Waggoner, S. L. Dowhower, and S. A. Gerrard. 2008. Rangeland vegetation and soil response to summer patch fires under continuous grazing. Arid Land Research and Management 22:228-241.

The Nature Conservancy. 2012. Zumwalt Prairie Weather Station Data. Available at: http://conserveonline.org/workspaces/ZumwaltPrairieWorkspace/documents/ zumwalt-prairie-weather-station-data-2005-2011/view.html. Accessed 24 October 2012.

Thurow, T. L., W. H. BlackBurn, and C. A. Taylor, JR. 1986. Hydrologic characteristics of vegetation types as affected by livestock grazing systems, Edwards Plateau, Texas. Journal of Range Management 39:505-509.

Thurow, T. L., W. H. BlackBurn, AND C. A. Taylor. 1988. Infiltration and interrill erosion responses to selected livestock grazing strategies, Edwards-Plateau, Texas. Journal of Range Management 41:296-302.

Tomanek, G. W. 1969. Dynamics of the mulch layer in grassland ecosystems. In: R. L. Dix and R. G. Beidleman [EDS.]. The grassland ecosystem: a preliminary synthesis. Fort Collins, C0, USA: Colorado State University. p. 225-240.

Vaezl, A. R., and S. H. R. SAdeghl. 2011. Evaluating the RUSLE model and developing an empirical equation for estimating soil erodibility factor in a semi-arid region. Spanish Journal of Agricultural Research 9:912-923.

Villamil, M. B., N. M. Amiotti, And N. Peinemann. 2001. Soil degradation related to overgrazing in the semi-arid southern Caldenal area of Argentina. Soil Science 166:441-452.

WALKER, J. W. 1995. Viewpoint: grazing management and research now and in the next millennium. Journal of Range Management 48:350-357.

Wander, M. M., S. J. Traina, B. R. Stinner, and S. E. Peters. 1994. Organic and conventional management effects on biologically-active soil organic-matter pools. Soil Science Society of America Journal 58:1130-1139.

Warren, S. D., T. L. Thurow, W. H. Blackburn, and N. E. Garza. 1986. The influence of livestock trampling under intensive rotation grazing on soil hydrologic characteristics. Journal of Range Management 39:491-495.

Weber, K. T., AND B. S. Gokhale. 2011. Effect of grazing on soil-water content in semiarid rangelands of southeast Idaho. Journal of Arid Environments 75:464470.

Wischmeler, W. H., and J. V. Mannering. 1969. Relation of soil properties to its erodibility. Soil Science Society of America Proceedings 33:131-137.

WyFFELS, S. A. 2009. Influence of stocking density on grazing beef cattle performance, diet composition foraging efficiency, and diet guality on a late-spring earlysummer native bunchgrass prairie [thesis]. Corvallis, OR, USA: Oregon State University. $124 \mathrm{p}$.

Zhao, Y., S. Peth, P. Hallett, X. Y. Wang, M. Giese, Y. Z. Gao, and R. Horn. 2011. Factors controlling the spatial patterns of soil moisture in a grazed semi-arid steppe investigated by multivariate geostatistics. Ecohydrology 4:36-48. 